\title{
Structure Evolution Mechanism Analysis of Ecosystem of Cyber-society Based on Hyper Cycle Theory
}

\author{
Xiaolan Guan ${ }^{1}$, Zhenji Zhang ${ }^{2}$ and Shugang Zhang ${ }^{2}$ \\ ${ }^{1}$ Beijing Institute of Graphic Communication, Beijing 102600, China \\ ${ }^{2}$ Beijing Jiaotong University, Beijing 100044, China \\ \{08113101,zhjzhang, 10113132\}@bjtu.edu.cn
}

\begin{abstract}
The internal subjects of Ecosystem of Cyber-society interact with the external demand, resources and technology constantly by fulfilling their functions, so thus form the cycle development process of Ecosystem of Cyber-society. And the way of interaction between them determines the high-speed and orderliness of the structure and function development of Ecosystem of Cyber-society to a certain extent. So based on the cross-disciplinary analysis and research, this paper uses the hyper cycle theory to analyze the formation and evolution process of the hyper cycle structure of Ecosystem of Cyber-society. The research shows that there are a variety of cycle patterns in Ecosystem of Cyber-society, and these cycle patterns keep pushing forward the development of Ecosystem of Cyber-society under the dynamic action of a number of driving forces.
\end{abstract}

Keywords: Ecosystem of Cyber-society, Hyper cycle, Structure, Types, Evolution

\section{Introduction}

The United States Department of Commerce introduced the theory of ecology into the research report entitled "Emerging Digital Economy" first in the mid-April 1998, and put forward the concept of "Internet ecology" [1]. Then the Chinese scholar Zhenyu Tian put forward the concept of "network ecology" first in his published paper in 1998 [2]. While the concept of "network ecosystem" was first put forward in the published paper of Qingfeng Zhang entitled "Network Ecology" in 2000, which analyzed the network system using the method of ecology based on the analysis of the problems on network, and then put forward the concept of "Network Ecosystem", and discussed the components, features and functions of the network ecosystem [3].

However, the proposal of the concept of "Ecosystem of Cyber-society" appeared just in the recent years. Professor Zhenji Zhang put forward this concept first in his published book "Ecology of Cyber-society" in July 2008 [4]. Then there are some new researches about it [5-9]. For example, Shan Wang discussed the phenomenon of self-organization and its evolution mechanism in the network society using both of the theory of self-organization and the theory of ecology and system, and provided a new direction to the understanding and research on the formation and evolution of Ecosystem of Cyber-society [10]. Min Yao analyzed and discussed the driving force mechanism of the network society using the theory and method of system dynamics based on the analysis of the overall architecture of Ecosystem of Cyber-society [11].

Although the above researches studied the Ecosystem of Cyber-society from different angles, they were still mainly concentrated on the micro level. The researches were not thorough enough, and most of them floated on the macro and the surface. It has not yet formed a complete research system and lack of research on the micro and internal structure, properties, and formation mechanism of Ecosystem of Cyber-society. Therefore, we need to find a new theory and method to explain the formation mechanism of 
Ecosystem of Cyber-society and find the root causes of the problem, in order to ensure the healthy, harmonious and orderly development of Ecosystem of Cyber-society.

The hyper cycle theory provides a new perspective to understand the formation and evolution process of Ecosystem of Cyber-society. A variety of driving forces promote the formation and rapid development of Ecosystem of Cyber-society. However, it is to be noted that during the process of formation and evolution of Ecosystem of Cyber-society, although these driving forces and the conditions are necessary, the way of combination is still very important in the case of these conditions and driving forces. The interaction between the various elements or groups of Ecosystem of Cyber-society need a certain way to achieve and the entire Ecosystem of Cyber-society would continue to evolve in a certain manner under the constraints of resources and environment driven by the driving forces. And the important role of the hyper cycle on Ecosystem of Cyber-society is that it can produce new forms and combinations continuously through the close integration and cross catalytic between populations.

The hyper cycle theory is proposed by Manfred Eigen in 1971, a physicist and chemist from the University of Berlin. He pointed out that the basic building mechanism of some seemingly very complex and special system is not so complicated, and the key is a cause and effect or continuous cycle of cause and effect. Once form the circulatory system, then form the so-called "self" and self-organized activities. The generation of hyper cycle is a basic way of evolutionary development, so it should be given enough attention to form a virtuous cycle of running in order to achieve the healthy, rapid and stable development of Ecosystem of Cyber-society on the basis of ecological balance.

\section{Analysis of the Structure of Ecosystem of Cyber-society}

The Ecosystem of Cyber-society is composed by a large number of subjects, and the relationships between them are very wide and close. The change of each subject is affected by the impact of other subjects' change, and would also cause the change of other subjects, while the subjects on each layer build the basis for the subjects on the upper layer, and also contribute to the realization of various functions of Ecosystem of Cyber-society, and then form a complex network structure with multi-levels and multi-functions. The Ecosystem of Cyber-society is open, so it is closely linked to the environment, and is able to interact with the environment. It is always in the status of dynamic evolution. The subjects of Ecosystem of Cyber-society interact with each other sporadically based on the local information, and there is no high-level control on the overall situation to coordinate the interaction between the subjects. At the same time, the Ecosystem of Cyber-society itself has certain predictive power to the future development and change, so it can learn continuously during the development process and thus restructure and improve its hierarchical structure and functional structure, in order to develop and change to the direction of better adaption to the environment.

The Ecosystem of Cyber-society is constituted by the resources, groups and related environment of network society, as shown in Figure 1 [12]. 


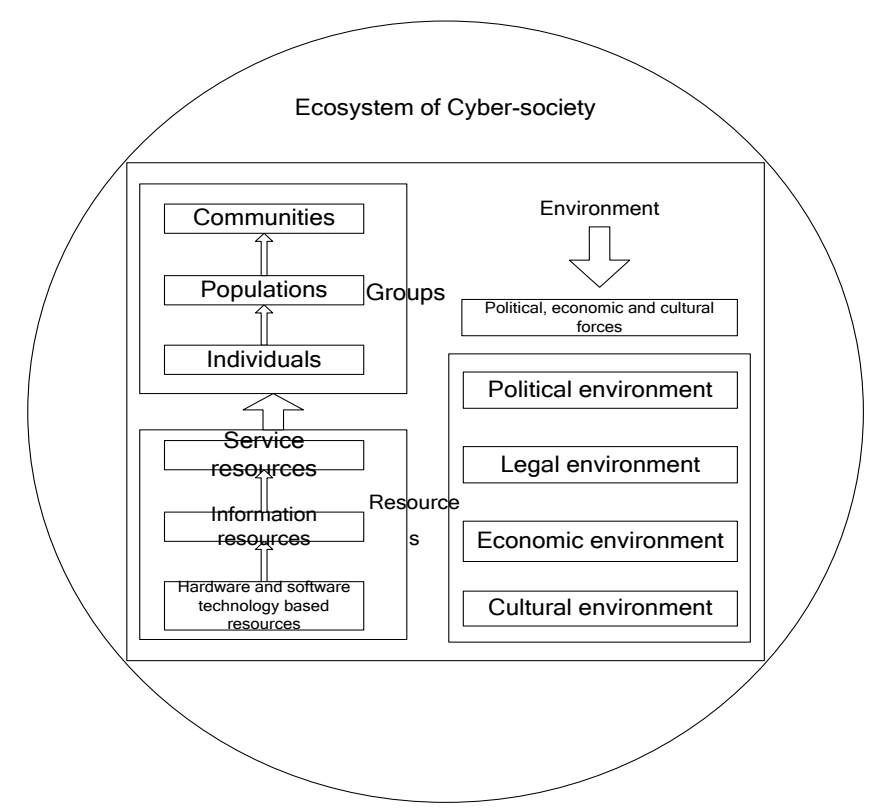

Figure 1. The Logical Structure of Ecosystem of Cyber-society

\subsection{Resources}

There are a wide variety of resources in Ecosystem of Cyber-society, and in general they can be divided into the following three categories, hardware and software technology based resources, information resources and service resources. As the most fundamental resources in Ecosystem of Cyber-society, the hardware and software technology based resources is the premise of the existence of the other two resources of information and service, while the service resources is built on the basis of the information resources. These three kind of resources influence with each other and they are inseparable, and thus constitute the hierarchical structure of Ecosystem of Cyber-society, in which the lower resources can provide a strong support for the upper resources.

\subsection{Groups}

The group is the only one subject that can take the initiative in Ecosystem of Cyber-society, and it is the most active element. The group in Ecosystem of Cyber-society can be divided in the following three levels from micro to macro, and those are individuals, populations and communities. The individuals refer to the subjects that are inseparable and can complete certain network behavior independently in the activities of Ecosystem of Cyber-society, including the natural individual Internet users and groups of individual namely virtual enterprises (or other organizations). And all the individual Internet users and the individual virtual enterprises that influence with each other and function as a whole to the outside world within a certain scope of Ecosystem of Cyber-society are called the population of Ecosystem of Cyber-society. They have same or similar ecological characteristics. The community of Ecosystem of Cyber-society refers to the collection with certain structure and functions composed by a variety of different populations of Ecosystem of Cyber-society in a certain environment, such as all the users in a web forum. These three levels overlap with each other, as shown in Figure 2. 


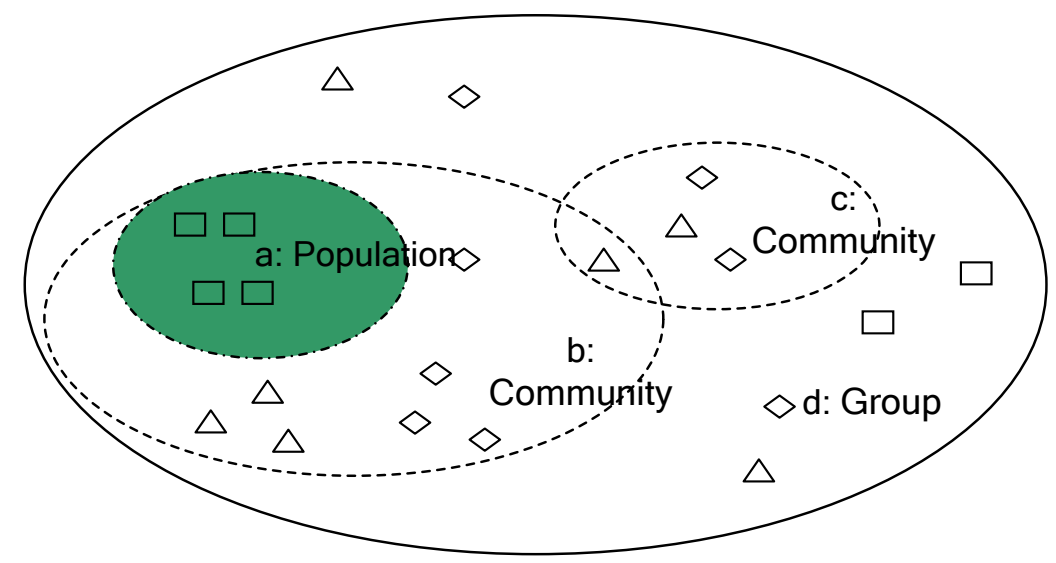

Figure 2. The Classification and Relationships between Groups in Ecosystem of Cyber-society

\subsection{Environment}

The environment of Ecosystem of Cyber-society is constituted by a variety of sub-environment that influence and interact with each other, including the political environment, legal environment, economic environment and cultural environment, as shown in Figure 3.

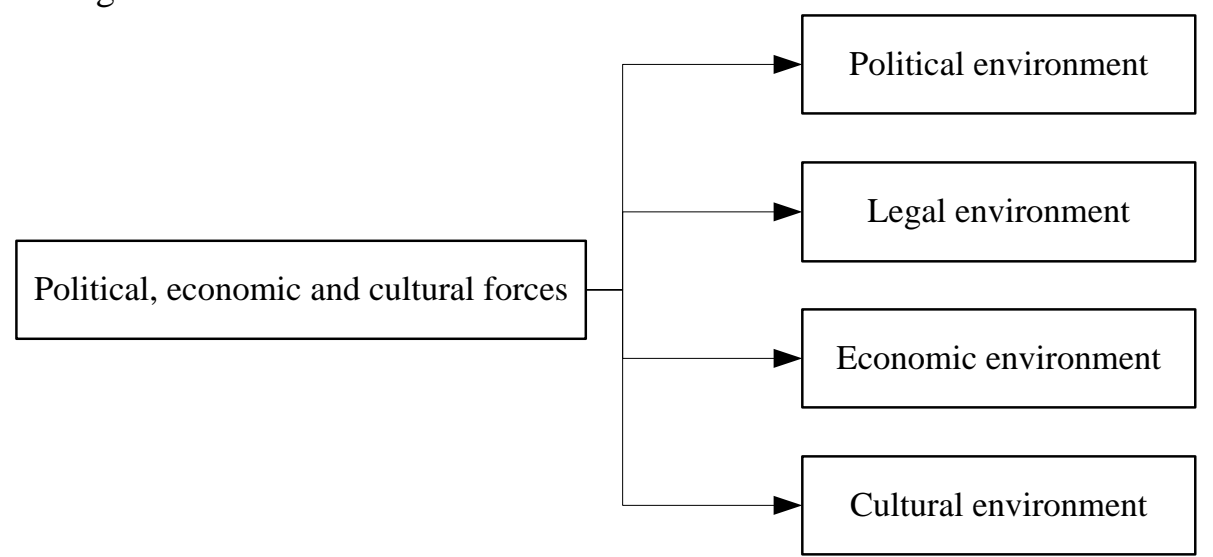

Figure 3. The Environmental Structure of Ecosystem of Cyber-society

\section{Modeling and Analysis of the Hyper cycle Evolution Process of Ecosystem of Cyber-society}

\subsection{Analysis of the Evolution Conditions of the Hyper Cycle Structure of Ecosystem of Cyber-society}

The hyper cycle structure can only exist in the evolution, and the existence and evolution of a hyper cycle structure must meet the following three preconditions: (1) A sufficiently large negative entropy flow to promote the metabolism of the structure. (2) A replication ability that strong enough to accumulate and inherit the system information. (3) A functional coupling between the subjects that strong enough to guarantee the existence and development of the structure. Only if meeting these three conditions, then there can be the hyper cycle structure with stable development and evolution. Otherwise, degradation is inevitable. Obviously, the Ecosystem of Cyber-society also meets these three conditions of forming the hyper cycle structure.

(1) The characteristic of openness - the formation source of the hyper cycle structure of 


\section{Ecosystem of Cyber-society}

The Ecosystem of Cyber-society is an open system, and it exchanges material and energy with the environment continuously. On the one hand, it has to input resources from the environment to maintain its own development, and on the other hand, it also has to output the effect that caused by its own metabolism to the environment of Ecosystem of Cyber-society. The Ecosystem of Cyber-society can maintain effective catalytic cycle and self-renewal through continuously absorbing the energy deficit that maintains its own evolution and output the surplus energy, so that it can develop and evolve from a low-order cycle structure to a high-order one in the optimal combination and characteristics collaboration within a larger area of the open system.

(2) The characteristic of recycling - the formation guarantee of the hyper cycle structure of Ecosystem of Cyber-society

The characteristic of recycling is a reliable guarantee to the formation of the hyper cycle structure of Ecosystem of Cyber-society. Since the Ecosystem of Cyber-society is a virtual society that built on the basis of a series of information technology and computer technology, so the multiple use and recycling of raw materials, products and wastes within the ecosystem is the hyper cycle characteristic of the system that would coexist for a long time and develop continuously. Similar to the relationship between producers, consumers and decomposers formed in the natural ecosystems, there are also relationships between the virtual enterprises or e-commerce business, that is to say an enterprise's waste can be used as raw materials for another enterprise, and the resources would be used optimally through the cooperation between enterprises.

(3) The characteristic of nonlinear interaction - the formation method of the hyper cycle structure of Ecosystem of Cyber-society

The changes of various elements of Ecosystem of Cyber-society are complex, since that the various elements interrelate and interact with each other. When the environment affects one or several elements of Ecosystem of Cyber-society, the Ecosystem of Cyber-society will not take the performance of these elements as results. However, these elements will act on other elements, and at the same time other elements will react to these elements, then the Ecosystem of Cyber-society will show some mutual changes. The changes of elements lead to not only quantitative changes, but they also lead to the changes of system morphology, structure and function, and this kind of change from quantitative change to qualitative change is the result of the nonlinear interaction. The reason why the network society is so colorful, bizarre, and why the network life is so diversified is just because of the nonlinear interaction in the evolution of Ecosystem of Cyber-society.

(4) The characteristic of people's participation - the formation particularity of the hyper cycle structure of Ecosystem of Cyber-society

There is difference between the formation of the hyper cycle structure of Ecosystem of Cyber-society and the general formation of a hyper cycle structure, and it mainly manifests as this process is often completed with people's awareness. The Ecosystem of Cyber-society is a social system that some people involved in, and it is a special system between natural system and artificial system. The formation of the hyper cycle structure of Ecosystem of Cyber-society relates to the problem of the quality of people and how to play the right role of people's initiative. The people not only have the characteristic of passivity in Ecosystem of Cyber-society, but they also have the characteristic of initiative, which has to be played effectively.

\subsection{Analysis of the Hyper Cycle Forces of Ecosystem of Cyber-society}

The hyper cycle forces of Ecosystem of Cyber-society are also the various driving forces that promote the formation and rapid development of Ecosystem of Cyber-society. 
They can bring energy into the system, and then the energy would function on all the levels of the system, so thus make the formation and development of Ecosystem of Cyber-society forward or backward. The hyper cycle forces that affect the formation and development of the hyper cycle structure of Ecosystem of Cyber-society include the progress of science (information) technology, improvement of social and economic development, innovation within the system, pull of social psychology, promotion of network culture, input of external resources, and the formulation of policies, laws and regulations, as shown in Figure 4.

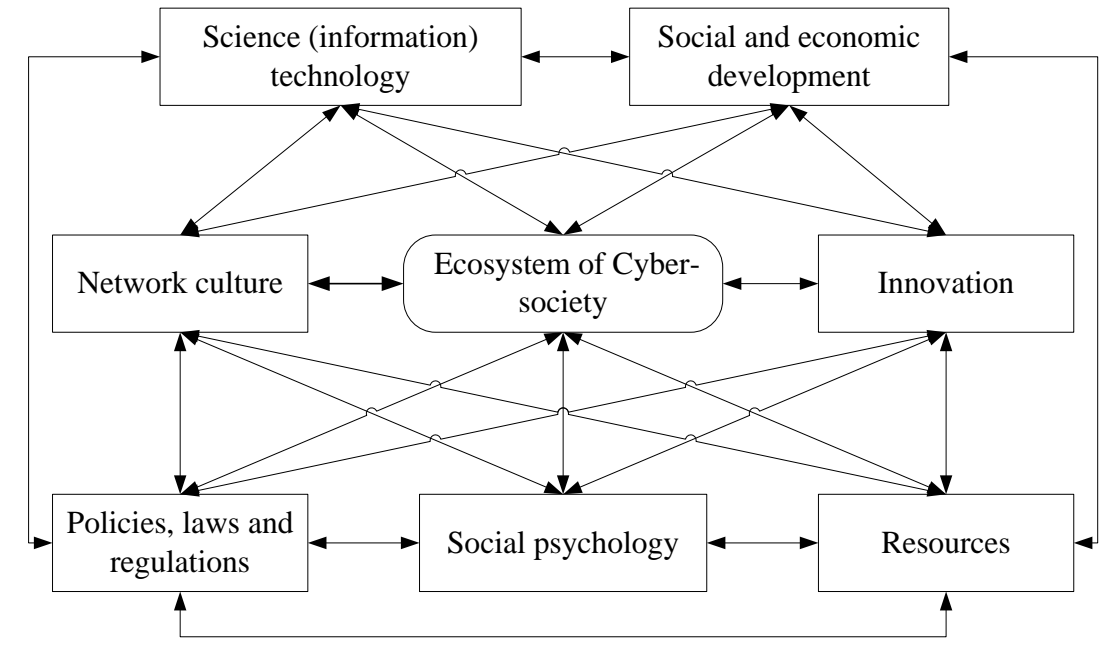

Figure 4. The Hyper Cycle Forces of Ecosystem of Cyber-society

\subsection{Analysis of the Hyper Cycle Formation Process of Ecosystem of Cyber-society}

According to the theory of Eigen, the evolution of living system is realized through the mechanism of self-replication, mutation and selection in the form of hyper cycle [13]. Similarly, as a living system, the formation and evolution of Ecosystem of Cyber-society also realizes through the form of hyper cycle. The subjects of Ecosystem of Cyber-society are the basic units of hyper cycle, and through the integration and cross-copy between them, there would be new forms, new structures and new features generated through the mechanism of mutation and selection, and thus form a coupling hyper cycle system.

We will take the hyper cycle between the population of Ecosystem of Cyber-society and the driving force of innovation as an example for analysis [14, 15].

Assume that $I_{1}$ and $I_{2}$ are two closely connected and abundant populations in Ecosystem of Cyber-society, the innovation learning ability of $I_{1}$ is $E_{1}$, and the innovation learning ability of $I_{2}$ is $E_{2}$. Each population has core competitiveness that distinguishes it from other populations, and at the same time, each population can also enhance their core competitiveness through their own innovation learning ability. There would be new core competitiveness generated through the integration of innovation learning ability and core competitiveness between different populations, and thus generate new populations. Since the combination way and tightness degree of the innovation learning ability and core competitiveness between different populations are different, so there are four kinds of coupling interaction between the two populations and the innovation learning ability, as shown in Figure 5. Here, $k$ represents the bonding strength between the innovation learning ability and population, the solid line represents that the strength is big and dashed line represents that the strength is small. 

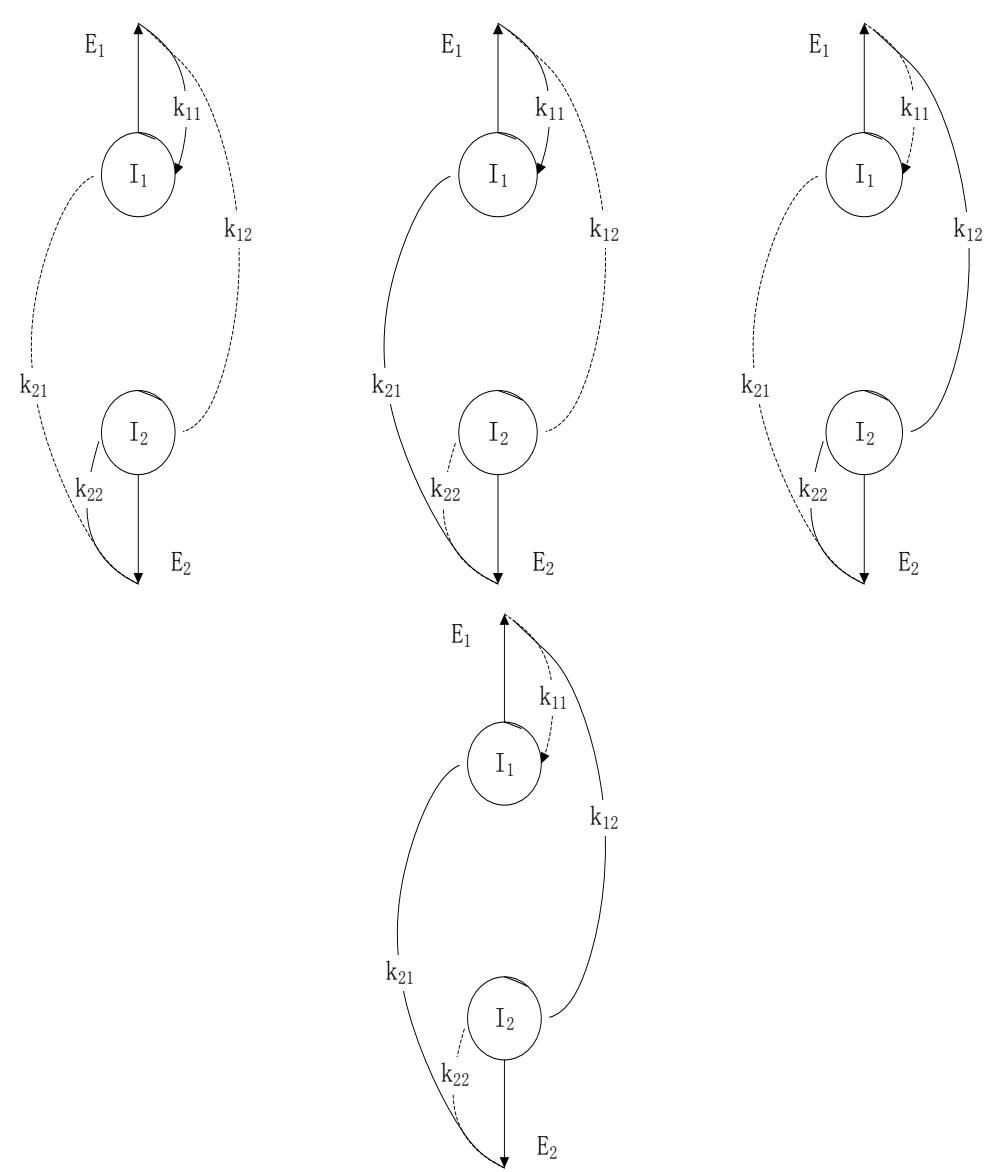

(a)

(b)

(c)

(d)

Figure 5. The Binary Hyper Cycle Evolution in Ecosystem of Cyber-society

(a) $k_{11}>k_{12}, k_{22}>k_{21}$, here, $I_{1}$ and $I_{2}$ are enhanced by there own innovation learning ability $E_{1}$ and $E_{2}$ in the form of hyper cycle, and the result is that the competition between these two subjects is intense, and the subsystem composed of $E_{1}$, $E_{2}, I_{1}$ and $I_{2}$ is in the status of unstable dynamic evolution. Even if there is occasional balance, the balance is short and fragile. As long as there is a tiny fluctuation, the balance will be broken, and then through the self-reinforcing of these two subjects, one competitor would survive, and the other one would die out. It is totally a random process that which competitor may be preserved.

(b) $k_{11}>k_{12}, k_{22}<k_{21}$, here, both $E_{1}$ and $E_{2}$ are conducive to $I_{1}$ not $I_{2}$, then the result is that the core competitiveness of $I_{1}$ is strengthened, and wins in the competition, while $I_{2}$ is in a disadvantage position in the competition, it would gradually disappears, and finally to be replaced by $I_{1}$.

(c) $k_{11}<k_{12}, k_{22}>k_{21}$, here, both $E_{1}$ and $E_{2}$ are conducive to $I_{2}$ not $I_{1}$, then the result is that the core competitiveness of $I_{2}$ is strengthened, and wins in the competition, while $I_{1}$ is in a disadvantage position in the competition, it would gradually disappears, and finally to be replaced by $I_{2}$.

(d) $k_{11}<k_{12}, k_{22}<k_{21}$, here, $E_{1}$ is conducive to $I_{2}$, and $E_{2}$ is conducive to $I_{1}$, then the result is that the core competitiveness of $I_{1}$ and $I_{2}$ are inseparable from each other's support, and both of them are unable to obtain relatively independent competitive 
advantage, so the Ecosystem of Cyber-society would eventually develop a self-reinforcing and interactive enhanced coupling mode of action, and thus establish the binary hyper cycle.

In the above analysis of four cases, the result of the three coupling modes in Figure 5 (a), Figure 5 (b), and Figure 5 (c) is that only one subject is retained, and the Ecosystem of Cyber-society can not evolve to a higher level, it will remain at the original level. There is stable hyper cycle between $I_{1}$ and $I_{2}$ only in Figure 5 (d), where the Ecosystem of Cyber-society can further evolve and develop to a higher level.

After the formation of binary hyper cycle structure in Ecosystem of Cyber-society, the hyper cycle will inevitably increase toward the direction of polyhydric hyper cycle through mutation. When there is a variant $I_{1}^{\prime}$ during the innovation learning process of $I_{1}$, as shown in Figure $6(\mathrm{a})$, then there are three kind of result for $I_{1}^{\prime}$, and those are either replace $I_{1}$, either die out, or incorporate into the hyper cycle. Only if the innovation learning ability $E_{1}^{\prime}$ of the variants $I_{1}^{\prime}$ is more conducive to enhance the core competitiveness of $I_{1}$ than the innovation learning ability $E_{2}$ to $I_{1}$, and the innovation learning ability $E_{2}$ of $I_{2}$ is also conducive to enhance the core competitiveness of $I_{1}^{\prime}$, then there would be a new cycle and a new population. $I_{1}^{\prime}$ would incorporate into the hyper cycle, and the binary hyper cycle will be expanded to ternary super cycle, as shown in Figure 6 (b). As the populations continue to mutate and naturally select, there would be more and more new populations and innovation learning abilities would incorporate into the hyper cycle, and thus forming a polyhydric hyper cycle, as shown in Figure 6 (c).

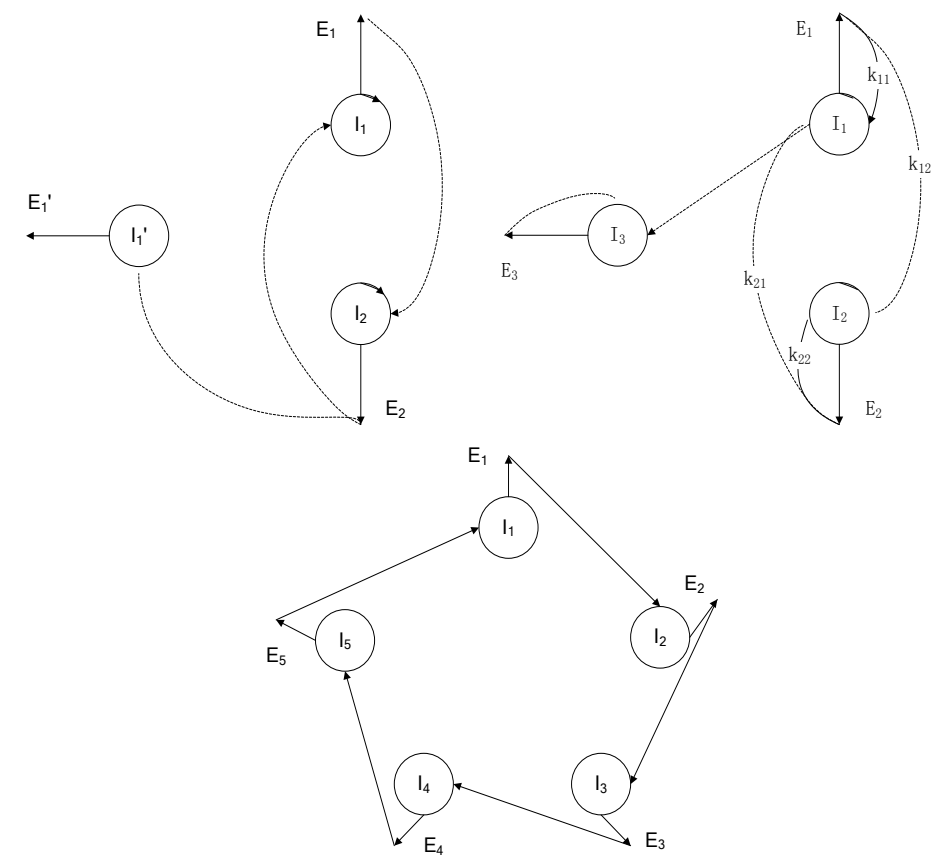

( a)

(b)

(c)

Figure 6. The Polyhydric Hyper Cycle in the Living System

\section{Application Research}

\subsection{The Hyper Cycle Types of Ecosystem of Cyber-society of China}

The hyper cycle phenomenon during the process of formation and development of Ecosystem of Cyber-society of China can be divided into the following five different 
levels from lower to higher and from simple to complex [16, 17]:

(1) The first level is called the self-reaction cycle of each individual population, and it is a self-replicating process on the whole;

(2) The second level is called the conversion reaction cycle of each individual population, and it is a self-regenerating process on the whole;

(3) The third level is called the catalytic reaction cycle between populations, and it is a process of catalytic chain on the whole;

(4) The fourth level is called the cross-reaction cycle between communities, and it is a cross-linking process on the whole. It is similar to the third level. However, the catalytic reaction cycle between populations emphasizes the interaction between populations of the same category, while the cross-reaction cycle between communities emphasizes the interaction between the populations of different levels.

(5) The fifth level is the so-called hyper cycle, and it refers to the cycle formed through the functional coupling link of catalytic cycle, namely the catalytic hyper cycle.

(1) The self-reaction cycle of each individual population

The self-reaction cycle of each individual population is also a self-replicating process, during which individuals in the populations disappear, and at the same time there would be new individuals emerging in with exactly the same quality. The existence of self-replication can ensure the sustainable development of the various populations in Ecosystem of Cyber-society, and it will not disappear because of the death of an individual, and thus ensure the species diversity of Ecosystem of Cyber-society.

(2) The conversion reaction cycle of each individual population

The conversion reaction cycle is the most simple and lowest level cycle between the various elements, and it is the organizational sequence in the initial level. In the Ecosystem of Cyber-society, the conversion reaction cycle is primarily generated in the individual populations and it is a cycle of resources, information and energy within the populations. As shown in Figure 7, it is similar to the production of the input-output system, by inputting raw materials, information technology, and knowledge and so on, then outputting network products and services. For example, a network marketing system obtains funds through selling goods, and initially the birth of the web pages on the Internet is only used to provide information and access to information. The various subsystems are independent of each other.

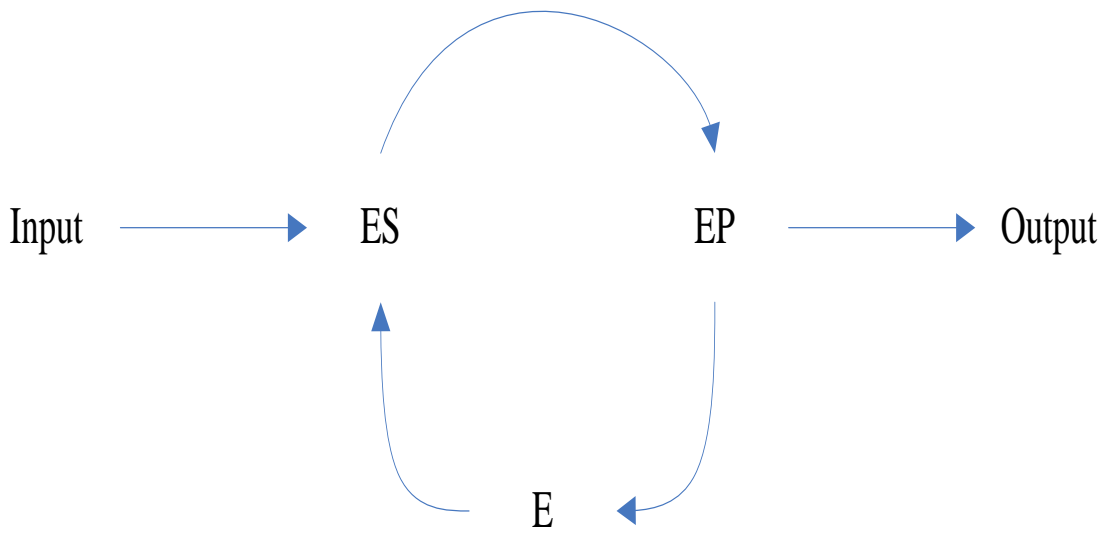

Figure 7. The Conversion Reaction Cycle in Ecosystem of Cyber-society 
(3) The catalytic reaction cycle between populations

The catalytic reaction cycle between populations is the cycle in a higher level than the reaction cycle, and it is the combination of a plurality of mutually catalytic reaction cycle, which means that the Ecosystem of Cyber-society has the mechanism of metabolism and self-replicating. It is a process of producing a catalyst (or reaction cycle) by another catalyst (or reaction cycle), and both of the process itself and its parts have the mechanism of self-replication, that is to say the catalysis of $A$ generates $B$, the catalysis of $B$ generates $C$, the catalysis of $C$ generates $D, \cdots \cdots$, and then the catalysis of $X$ generates $A$. Here, the product is a catalyst, and it has the capacity of production. The production speed of the product increases or grows nonlinearly according to the exponential. At the same time, the catalytic reaction cycle has the characteristic of independency, and it is not subject to the environmental constraints, so it can evolve towards the direction of information self-replicating.

The catalytic reaction cycle between populations mainly exists in the various populations of Ecosystem of Cyber-society. Take the provide of a network service for an example, as shown in Figure 8, first the network content providers collect information from the environment of Ecosystem of Cyber-society, then the technical personnel use the network equipment to process the information and add some information technology and knowledge into it, then output the network products or services into Ecosystem of Cyber-society, while the subjects of Ecosystem of Cyber-society would consume these products or services and give feedback information to the environment of Ecosystem of Cyber-society. The network content providers obtain the feedback information from Ecosystem of Cyber-society again and improve the processing of products or services, and then start a new cycle.

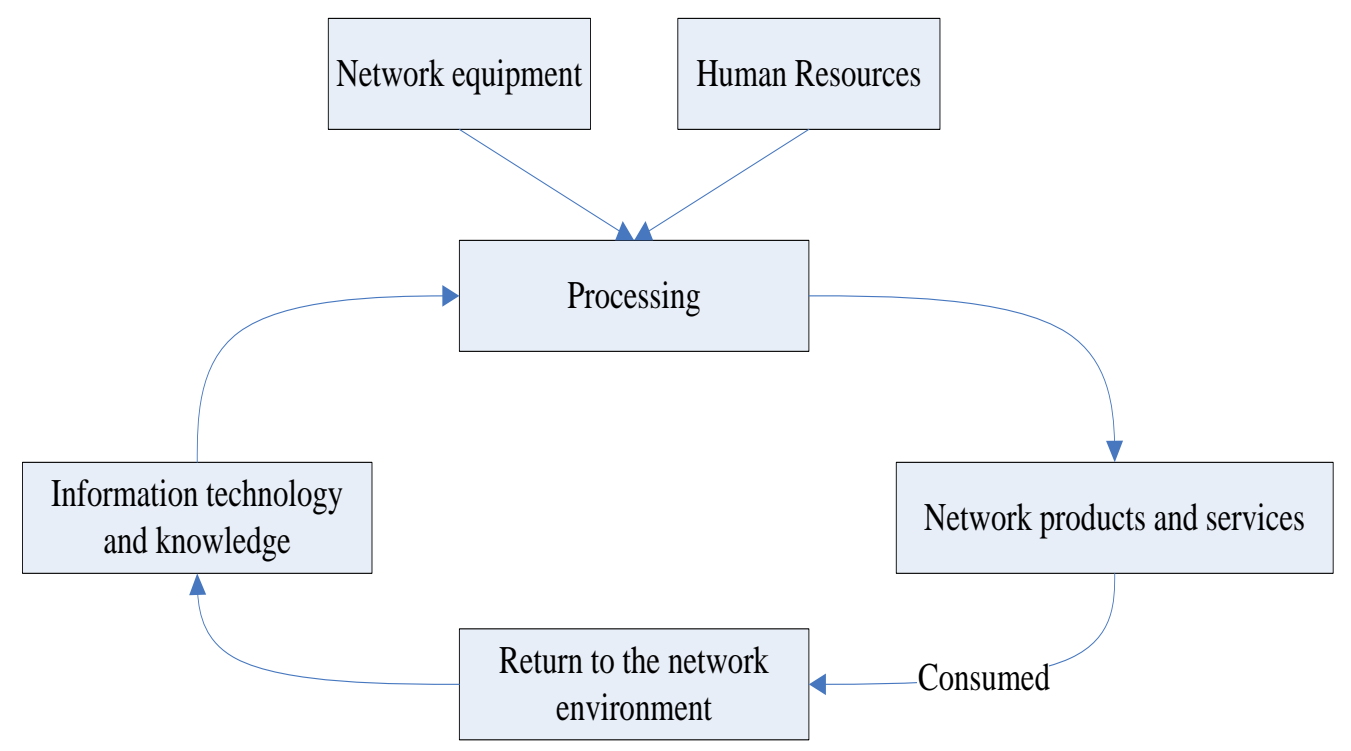

Figure 8. The Catalytic Reaction Cycle in Ecosystem of Cyber-society

(4) The cross-reaction cycle between communities

The cross-reaction cycle between communities is also the cycle of the reaction cycle, and it is more advanced than the conversion reaction cycle. There are cross-catalyzed relationships between the various subsystems of the different member systems, and they form an accessible, crisscross, and orderly circulatory system, as shown in Figure 9. 


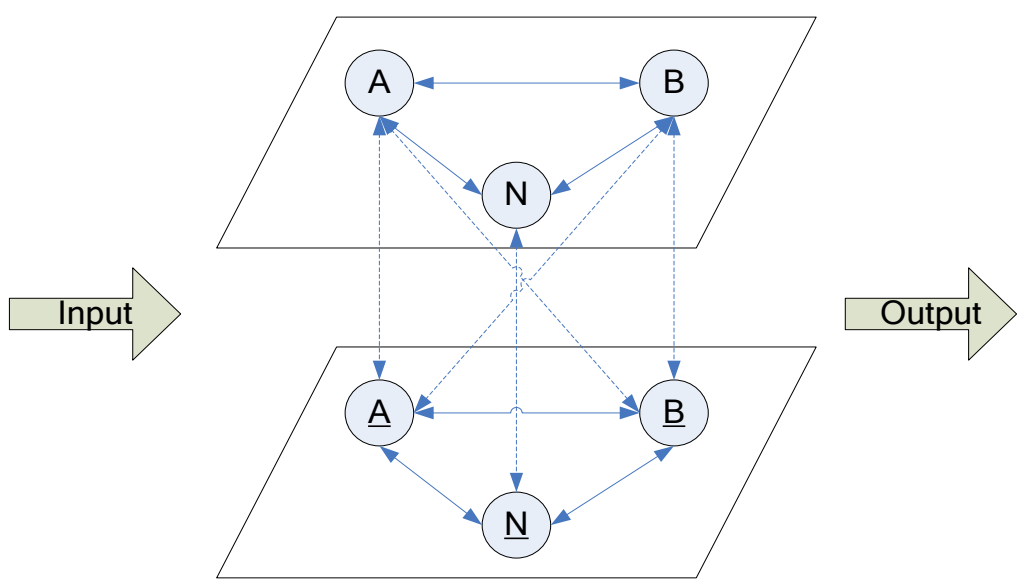

\section{Figure 9. The Cross-Reactivity Cycle between Different Levels of System}

There is also such cross-reaction cycle in Ecosystem of Cyber-society, that is to say the process of various communities in Ecosystem of Cyber-society react with each other through the catalytic loop. Take the e-commerce ecological communities in Ecosystem of Cyber-society as an example. The e-commerce ecological communities are generally composed by the population of e-commerce application development and support, population of e-commerce services, and the population of e-commerce applications, as shown in Figure 10. These populations linked with each other on the basis of their respective reaction cycle and the conversion reaction cycle, and thus form a cross-reaction cycle.

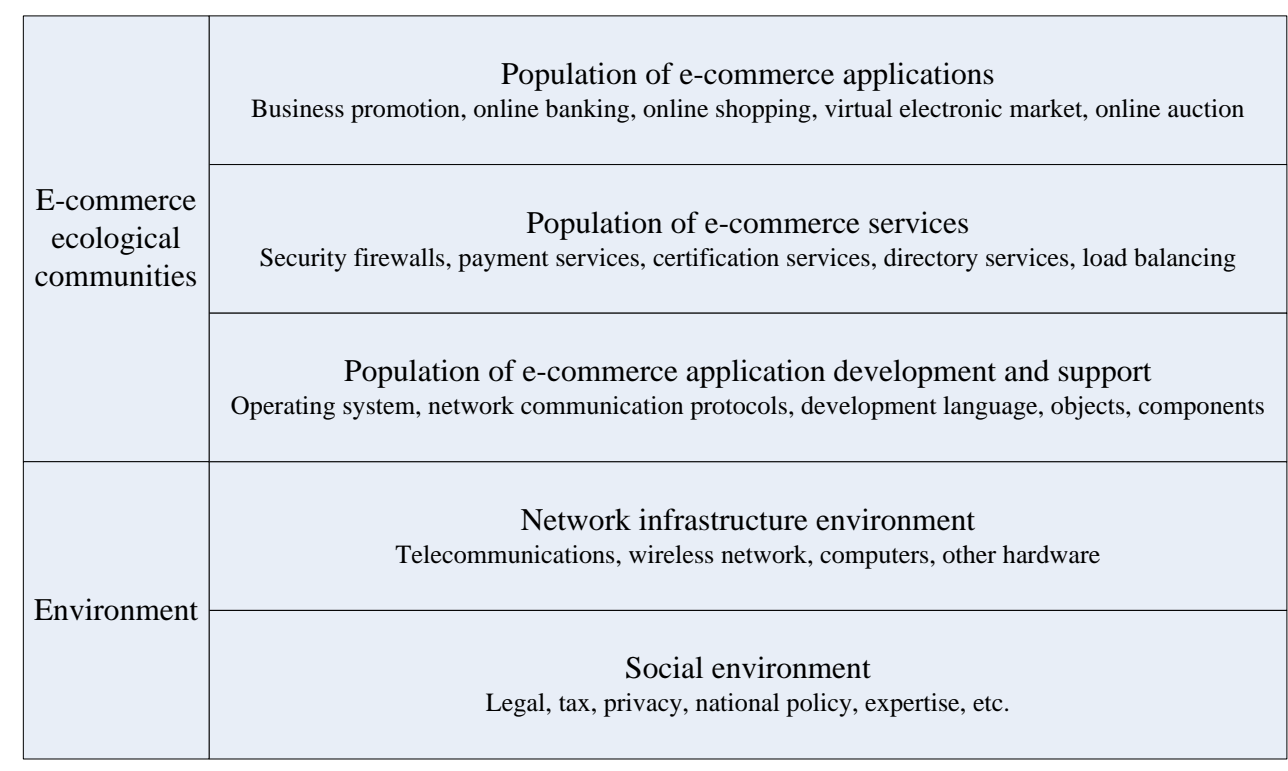

Figure 10. The E-commerce Ecological Communities

As shown in Figure 11, the population of e-commerce service $A_{1}$ is the most fundamental population, and it can provide a variety of hardware and software resources to support or give technical guidance $E_{2}$ to the population of e-commerce application development and support while constantly adapt to the environmental changes. And the population of e-commerce application development and support $A_{2}$ would provide a variety of products or services support for the population of e-commerce applications $E_{3}$ under the support of $E_{2}$, and also continue to accumulate experience to enhance their capacity during the development process. Then $E_{3}$ would guide the activities of the other population of e-commerce 
application $A_{3}, \cdots \cdots$ so constantly repeated the cycles, and each conversion reaction cycle can provide experiences, lessons and catalytic support to other reaction cycles, and at the same time the work of each conversion reaction cycle in a certain phase can also provide experiences, lessons and catalytic support to the next phase, and thus form the cross-reaction cycle to maintain the sustainable, healthy and rapid development of Ecosystem of Cyber-society.

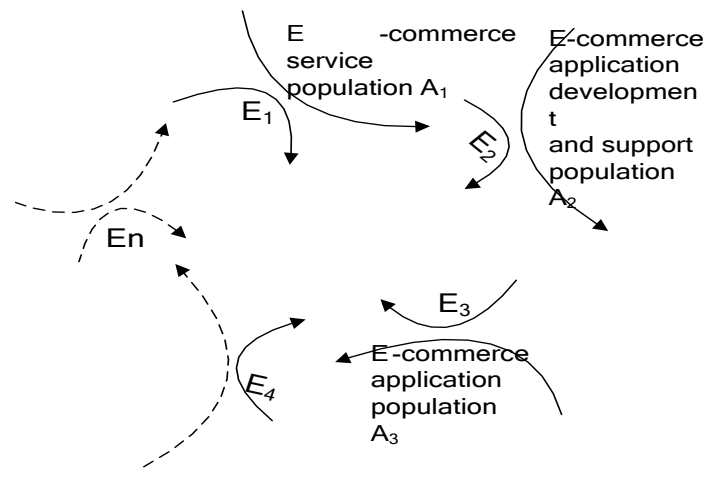

\section{Figure 11. The Cross-reactivity cycle between Different Levels of Ecosystem of Cyber-society}

(5) The hyper cycle

The hyper cycle is the cycle that formed through the functional linkage between the cycles based on the cross-reaction cycle. The hyper cycle in Ecosystem of Cyber-society is not only a facial integration of circulatory system, but it is also an integration of functions. It not only has the characteristics of self-regenerating, self-replicating and so on that the low-level cycle has, but it also has the characteristics of self-selection and self-optimization, and thus makes Ecosystem of Cyber-society develop and evolve toward a higher level of ordered status constantly.

\subsection{Analysis of the Hyper Cycle that Takes the Internet users as the Core}

The hyper cycle is a kind of type that widely exists in Ecosystem of Cyber-society due to the interaction and evolution between the subsystems. Various elements of the system has to evolve to the status of hyper cycle finally through the self-reaction cycle, conversion reaction cycle, catalytic reaction cycle and cross-reaction cycle, and thus make Ecosystem of Cyber-society constantly develop and form a giant system with complex structure and relations.

The Ecosystem of Cyber-society of China evolves to the status of hyper cycle after continuous development and evolution, and it is inseparable with the active participation of the subjects of Ecosystem of Cyber-society of China. Here, the subjects of Ecosystem of Cyber-society of China mainly refer to the Internet users and virtual e-commerce enterprises. The subjects of Ecosystem of Cyber-society of China are not only affected by the system, but they also constantly improve the system. Without the participation of the subjects of Ecosystem of Cyber-society, there would not be the formation of hyper cycle of Ecosystem of Cyber-society of China no matter how the modern science (information) technology develops.

Take the Internet user for an example. The Internet user is a population that has its own subjective awareness in Ecosystem of Cyber-society, and they play two roles when using the computer and the network, the subject and the object. On the one hand, as a object, the Internet user is a passive recipient when using the network, and he can learn and recognize the objects that exist objectively by their ability during this process, but the role that he plays in this case on the formation and development of Ecosystem of Cyber-society is very small. On the other hand, as a conscious group, the Internet user would demonstrate his initiative of the subject, and the Internet user would not simply choose to accept or use the computer and the network with such capacity. 
Driven by the two driving forces of "interests" and "benefits" of the Internet users, the elements and subsystems in the Ecosystem of Cyber-society of China organically combine together through the structure or functions, and develop into the cross-reaction cycle and then hyper cycle via the self-reaction cycle, conversion reaction cycle and catalytic reaction cycle, as shown in Figure 12. For example, the Internet users can put forward their own proposals or views to this emerging medium during the process of use, and even some Internet users can find the problems and improve themselves. This seemingly minor change seems to be very small, but be aware that the number of Internet users in Ecosystem of Cyber-society of China is very huge, and this number is constantly increasing. Due to the use of the Internet users, the network is promoted to continuously progress and develop, and ultimately getting more sophisticated. And the more influential Internet users among them are the computer technicians. They are thinking about and committed to improving the network when they use the network. Of course, there are also negative examples, such as the hackers and virus writers, and their behavior has brought great harm to Ecosystem of Cyber-society of China. But from another point of view, their behavior also incentives or promotes people to enhance the network security, and make the network society more perfect. In order to obtain bigger "benefits", some e-commerce enterprises change their technology, service, and marketing according to the needs of their Internet user customers or potential customers, and then affect the entire Ecosystem of Cyber-society of China.

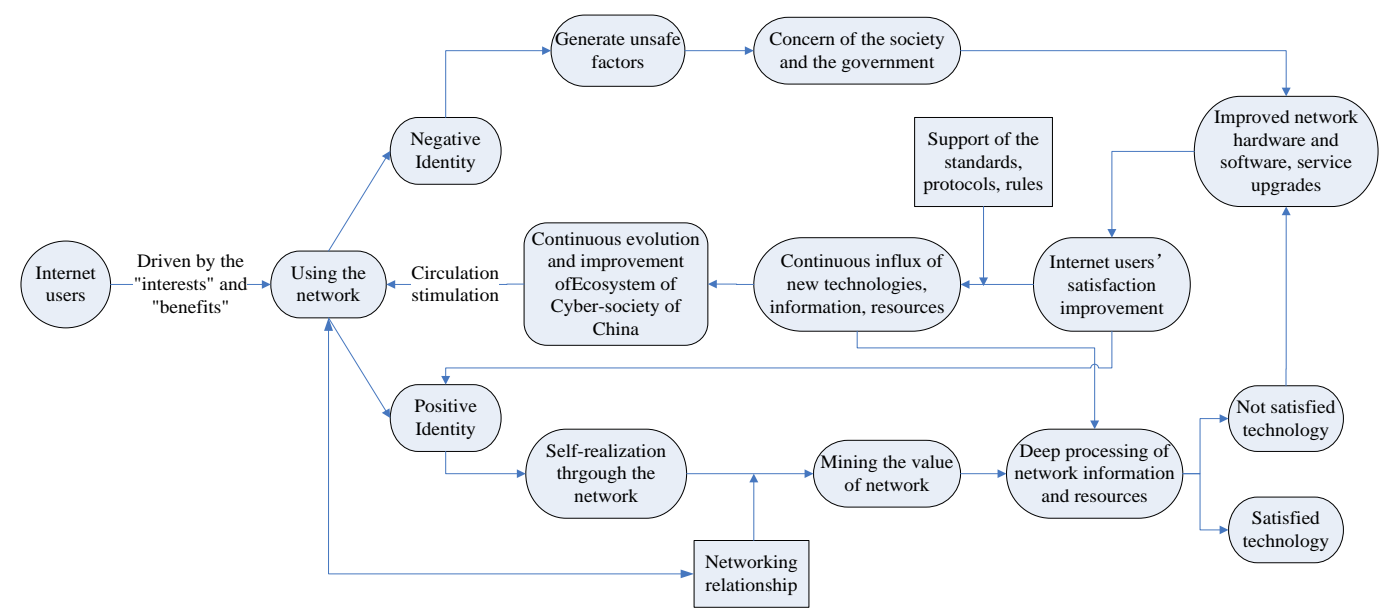

Figure 12. The Hyper Cycle that takes the Internet Users as the Core in the Ecosystem of Cyber-society of China

\section{Conclusions}

Using the hyper cycle theory and based on the cross-disciplinary analysis and research, this paper analyzes the formation and evolution process of the structure of Ecosystem of Cyber-society. The research shows that there are a variety of cycle patterns in Ecosystem of Cyber-society, and there are not only the self-reaction cycle of each individual population, conversion reaction cycle and catalytic reaction cycle between populations, but there are also the cross-reaction cycle between communities and the hyper cycle that takes the Internet users as the core. These cycle patterns keep pushing forward the development of Ecosystem of Cyber-society under the dynamic action of a number of driving forces. This is also the way of formation and evolution of Ecosystem of Cyber-society.

\section{Acknowledgements}

This work is partially supported by the General Research Project (18190113002) and the Quality Improvement Project of Personnel Training (03150113016) of Beijing Municipal Education Commission, and also the Institute Level Project (E-b-2012-20) and the Course Construction Project (22150112088) of Beijing Institute of Graphic Communication. 


\section{References}

[1] United States Department of Commerce, Emerging Digital Economy, (1998) April.

[2] Z. Tian, Network Ecology, Software World, no. 2, (1998).

[3] Q. Zhang, “Theory of Network Ecology”, Information and Documentation Work, no. 4, (2000), pp. 2-4.

[4] Z. Zhang and R. Zhang, "Ecology of Cybersociety", Publishing House of Electronics Industry, (2008) July.

[5] J. Zuo, “The Ecological Stability Research of Network Society Community”, Beijing Jiaotong University, (2008) June.

[6] Z. Tian, "Research and Application on Network Community Enterprise Niche Models", Beijing Jiaotong University, (2008) June.

[7] W. Xiaohong, "Research on Competition and Distribution of Network Resources in Network Ecosystem”, Beijing Jiaotong University, (2009) June.

[8] J. Feng, "Research on the Coordinated Development between Internet Users and Network Environment of the Ecosystem of Cyber-society”, Beijing Jiaotong University, (2010) June.

[9] J. Liu, "Research on the Stability Evaluation of the Network Social-Ecological System”, Beijing Jiaotong University, (2010) June.

[10] S. Wang, "Research on the Evolution of the Ecosystem of Cyber-society Based on Self-Organization Theory”, Beijing Jiaotong University, (2010) June.

[11] M. Yao, "Research on Thrust Mechanism of the Network Social-Ecological System”, Beijing Jiaotong University, (2010) June.

[12] X. Guan, "Research on the Formation Mechanism of Ecosystem of Cyber-society", Beijing Jiaotong University, (2011) July.

[13] Y. Yang and H. Sun, "Study on the Mechanism of the Forming and Evolution of the Firm's Innovation Networks Based on HyperCycle", Technoeconomics \& Management Research, no. 2, (2008), pp. 24-25.

[14] E. Takahashi, K. Kumatani and T. Chujo, "Evolution of network society and technological innovation", Fujitsu Scientific and Technical Journal, vol. 45, no. 4, (2009) October, pp. 331-338.

[15] M. Granatt and A. Paré-Chamontin, "Cooperative structures and critical functions to deliver resilience within network society”, International Journal of Emergency Management, vol. 3, no. 1, (2006), pp. 52-57.

[16] Z. He and W. Li, "The Research on the Integrated Innovation Mechanism of the Complex Products System on Hypercycle Theory”, SCIENTIFIC MANAGEMENT RESEARCH, vol. 28, no. 2, (2010) April, pp. 1-5.

[17] J. Wan and X. Gu, "Study on the Mechanism of the Evolution of Knowledge Networks Based on Hypercycle Theory”, Information Science, vol. 28, no. 6, (2010) June, pp. 1229-1232. 